\title{
In Reference to "The Effect of a Rapid Response Team on Resident Perceptions of Education and Autonomy"
}

\author{
Nancy H Stewart, DO ${ }^{1}$, Audrey Tanksley, MD², Vineet M Arora, MD, MAPP² \\ ${ }^{1}$ Department of Hospital Medicine, University of Chicago, Chicago, Illinois; '2Department of General Internal Medicine, University of Chicago, Chicago, \\ Illinois.
}

We read with great interest the study by Butcher and colleagues $^{1}$ on resident perceptions of rapid response teams (RRTs) with regard to education and autonomy. We found it interesting to note that one-third of residents felt the nurse should always notify the primary resident when calling an RRT. Nursing literature demonstrates that ambivalence exists on when to notify the physician, ${ }^{2}$ thus suggesting nurse-physician interactions are still suboptimal and an area for future improvement. Given the focus on interprofessional training and practice by both the Accreditation Council of Graduate Medical Education and Liaison Committee on Medical Education, ${ }^{3,4}$ RRTs provide a perfect opportunity to improve interprofessional training and practice through better physician-nurse collaboration.

Interestingly, the future of RRT activation can also be streamlined to avoid nurse-physician conflicts about who should be notified. For example, the technology exists for automated alerts in the electronic medical record to trigger when a patient decompensates, ${ }^{5}$ thereby acti- vating an RRT. One can imagine this technology circumvents the physician and nurse when initiating the RRT. Given the potential uses of such technology, future studies regarding physician autonomy with automatic triggering of an RRT will be equally valuable.

\section{References}

1. Butcher BW, Quist CE, Harrison JD, Ranji SR. The effect of a rapid response team on resident perceptions of education and autonomy. J Hosp Med. 2015;10(1):8-12.

2. Astroth KS, Woith WM, Stapleton SJ, Degitz RJ, Jenkins SH. Qualitative exploration of nurses' decisions to activate rapid response teams. J Clin Nurs. 2013;22(19-20):2876-2882.

3. Iobst W, Aagaard E, Bazari H, et al.; Internal Medicine Milestone Group. The Internal Medicine Milestone Project. The Accreditation Council for Graduate Medical Education and The American Board of Internal Medicine. Available at: https://www.acgme.org/acgmeweb/ Portals/0/PDFs/Milestones/InternalMedicineMilestones.pdf. Accessed February 12, 2015.

4. Liaison Committee on Medical Education. 2013 summary of new and revised LCME accreditation standards and annotations. Available at: http://www.lcme.org/2013-new-and_revised-standards-summary.pdf. Accessed February 12, 2015.

5. Churpek MM, Yuen TC, Park SY, Meltzer DO, Hall JB, Edelson DP. Derivation of a cardiac arrest prediction model using ward vital signs. Crit Care Med. 2012;40(7):2102-2108. 